\title{
Effects of post-settlement mortality on size and parasite load in juvenile Diplodus vulgaris and D. sargus in the Mediterranean
}

\author{
Serge Planes ${ }^{1, *}$, David Lecchini ${ }^{2}$, Pascal Romans ${ }^{1,3}$, Suzanne C. Mills ${ }^{1}$ \\ ${ }^{1}$ UMR 5244 CNRS - EPHE - UPVD, Université de Perpignan, 66860 Perpignan, France \\ ${ }^{2}$ Institut de Recherche pour le Développement, Centre IRD Noumea, UR 128 CoReUs, 98848 Noumea, New Caledonia \\ ${ }^{3}$ Present address: Observatoire Océanologique de Banyuls - UM 2348, BP 44, 66651 Banyuls-sur-Mer, Cedex, France
}

\begin{abstract}
This study explored how mortality processes influence life history traits of recently settled juvenile fishes (Diplodus vulgaris and D. sargus) in the Mediterranean. Mortality was estimated by measuring the decrease in abundance of a cohort from settlement to 4 mo post-settlement. Growth and parasite load were simultaneously measured over time to determine those phenotypes more susceptible to mortality. Diplodus spp. juvenile mortality was between 71 and $81 \%$ over the 4 mo period. A decrease in the coefficient of variation in size over time suggests that mortality may influence growth of both Diplodus species. A decrease in parasite abundance of both Diplodus species $60 \mathrm{~d}$ after settlement suggests that fish with higher parasite loads may have been more susceptible to mortality. Overall, mortality did not act randomly in D. vulgaris and D. sargus cohorts, as the variance in both size and parasite abundance of recently settled juveniles was not comparable to that of the adult population; only larger, parasite-free individuals survived.
\end{abstract}

KEY WORDS: Mortality processes • Selection • Parasites $\cdot$ Growth $\cdot$ Life history Resale or republication not permitted without written consent of the publisher

\section{INTRODUCTION}

A fundamental goal in population ecology is to understand the processes that influence individuals to survive to reproduction (Kingsolver et al. 2001). Predation is often considered an important causal factor in structuring terrestrial and aquatic populations, as it can be a major selective force in the evolution of organism structure and function (e.g. life history traits, morphology, sexual dimorphism, activity times and habitat use; reviewed by Fenberg \& Roy 2008). The critical period of high mortality for marine species (fish and invertebrates) that have a bipartite life cycle with a planktonic larval stage occurs during the transition of pelagic larvae from the open ocean to a benthic habitat (i.e. settlement phase; reviewed by Werner 1988). The small size of recently settled post-larvae/juveniles renders them susceptible to a wide range of predators, and predation is among the dominant factors influencing juvenile survival of marine species (e.g. Almany \&
Webster 2006, Lecchini et al. 2007, Allen 2008). Indeed, mortality is assumed to be greatest at the time of settlement or soon thereafter: between 30 and $90 \%$ of juveniles are removed by predation within the first weeks after settlement (e.g. Doherty 2002, Almany \& Webster 2006, Allen 2008). In some species, losses may be as great as $60 \%$ during the first night of settlement on a reef (Doherty et al. 2004). Furthermore, high predation mortality during settlement is not restricted to marine species; amphibians suffer elevated mortality rates from predation when moving from aquatic larval habitats to terrestrial adult habitats (Arnold \& Wassersug 1978).

In general, these examples suggest that life stage transitions may result in high mortality as relatively naïve individuals enter new habitats and encounter a suite of more experienced and opportunistic predators. Although life stage transitions account for only a small proportion of a species' total life span, small changes in the way in which mortality acts may have profound 
effects on the number of individuals reaching the adult phase, as well as the phenotypes of those individuals (e.g. Stearns 1992, Kingsolver et al. 2001, Fenberg \& Roy 2008). It is of particular interest to determine whether post-settlement mortality acts indiscriminately during life stage transitions, or in other words, whether all recently settled juveniles have a similar chance of being removed from the population, or whether a particular phenotype is more susceptible. The majority of the literature on selective mortality of marine species during the first post-settlement months has emphasised body size, condition or larval growth history without considering other aspects (e.g. Sogard 1997, Vigliola \& Meekan 2002, Hoey \& McCormick 2004, Meekan et al. 2006, Gagliano et al. 2007, Allen 2008).

In this study, a cohort of both Diplodus sargus (Linneaus, 1758) and D. vulgaris (Saint-Hilaire, 1817) (coastal marine sparid fishes abundant in the Mediterranean Sea) were monitored from settlement for $4 \mathrm{mo}$, when juveniles are known to move to adult habitats. The term 'cohort' refers to individuals that settle over a short period of time (within $1 \mathrm{~d}$ ) in the same settlement habitat (Planes et al. 1999). Mortality was estimated by measuring the decrease in population size of the cohort. Growth and parasite infection were simultaneously measured to gain insights into those phenotypes more susceptible to mortality.

\section{MATERIALS AND METHODS}

Sampling strategy. Two sampling sites were chosen along the Mediterranean coast in the southwest of France: Banyuls consists of 3 similar small bays (each $200 \mathrm{~m}$ wide), spaced $100 \mathrm{~m}$ apart along a rocky coast. St Marie consists of 3 similar artificial rocky jetties (each $5 \mathrm{~m}$ wide and $70 \mathrm{~m}$ long), each spaced $350 \mathrm{~m}$ apart and originally built to maintain the coastline's sandy beaches. Each jetty extends from the beach offshore to a depth of $2.5 \mathrm{~m}$, with only sand between the jetties. As Diplodus sargus and D. vulgaris juveniles show very limited movement (only about $50 \mathrm{~m}$ around their shallow rocky settlement habitats) and avoid crossing unsuitable habitats such as sandy areas (Harmelin-Vivien et al. 1995, Planes et al. 1998), we assumed that fish did not move between bays or jetties. Moreover, visual underwater surveys showed that the bays and jetties were the only settlement habitats of $D$. sargus and $D$. vulgaris in the sampling area (Romans 2003). D. vulgaris were sampled at both sites, whereas $D$. sargus were only sampled at St Marie. Within each site, 3 different protocols were carried out at the 3 different bays or jetties.

Settlement survey. All Diplodus juveniles were removed daily from the central jetty at St Marie and the central bay at Banyuls in order to estimate both daily settlement rates and to verify that juveniles do not move between jetties or bays. All $D$. vulgaris and $D$. sargus were monitored daily during the winter (22 November 2002 to 4 April 2003) and summer (1 May 1999 to 30 June 1999) seasons, respectively, to evaluate settlement patterns. Monitoring was conducted by underwater visual counting along the jetty or inside the bay (for more details about visual counting, see Harmelin-Vivien et al. 1985), and then all Diplodus were removed with small nets.

Mortality. The southernmost jetty and bay were used to estimate mortality of a single Diplodus cohort. Once a Diplodus cohort was identified on the first day of its settlement (defined as Day 0), mortality was estimated by measuring the decrease in population abundance of the cohort the following days after settlement: Days 7, 15, 30, 60 and 120. The survey consisted of 3 successive replicates of underwater visual counting along the jetty or inside the bay (Harmelin-Vivien et al. 1985).

Growth and parasitism. The northernmost jetty and bay were used to sample for growth and parasites over time. In total, 20 individuals were randomly sampled from the Diplodus cohort (using small hand nets with all precautions taken to ensure random collection; Romans 2003) at each sampling date (Day 0, 7, 15, 30, $60,120)$. Growth corresponds to the change in standard length of 20 individuals compared to the previous sampling date measured using callipers. The variance in length among individuals was used to compute the coefficient of variation in size. Parasite abundance (total number of monogeneans on the gills, cestodes in the intestine and digeneans encysted in the muscles) and parasite prevalence ( $\%$ of parasitised fish) were measured using the same 20 individuals.

Statistics. For all analyses, the Diplodus sargus cohort at St Marie and the $2 \mathrm{D}$. vulgaris cohorts at Banyuls and St Marie were treated as 3 species. Fully factorial 2-way analyses of variance (ANOVAs), with time and species as the 2 factors, were carried out on growth and parasitism. The assumptions of normality and heteroscedasticity were met by transforming the data $(\log (x+1))$.

\section{RESULTS}

\section{Settlement survey}

Daily settlement surveys showed peaks in settlement of Diplodus larvae: $50 \%$ of the total $172 \mathrm{D}$. vulgaris larvae that recruited at Banyuls between November and April settled on 10 December; $65 \%$ of the total $1741 D$. vulgaris larvae that recruited at St Marie between 
November and April settled on 13 December; and 82\% of the total $280 \mathrm{D}$. sargus larvae that recruited at St Marie between May and June settled on 12 June (Fig. 1). The fish cohorts that settled during these peaks were selected for monitoring over $4 \mathrm{mo}$, and the date of each peak was defined as Day 0.

\section{Mortality}

After 4 mo post-settlement, mortality of Diplodus vulgaris cohorts was 71.4 and $76.5 \%$ at Banyuls and St Marie, respectively (Fig. 2a,b). The decrease in
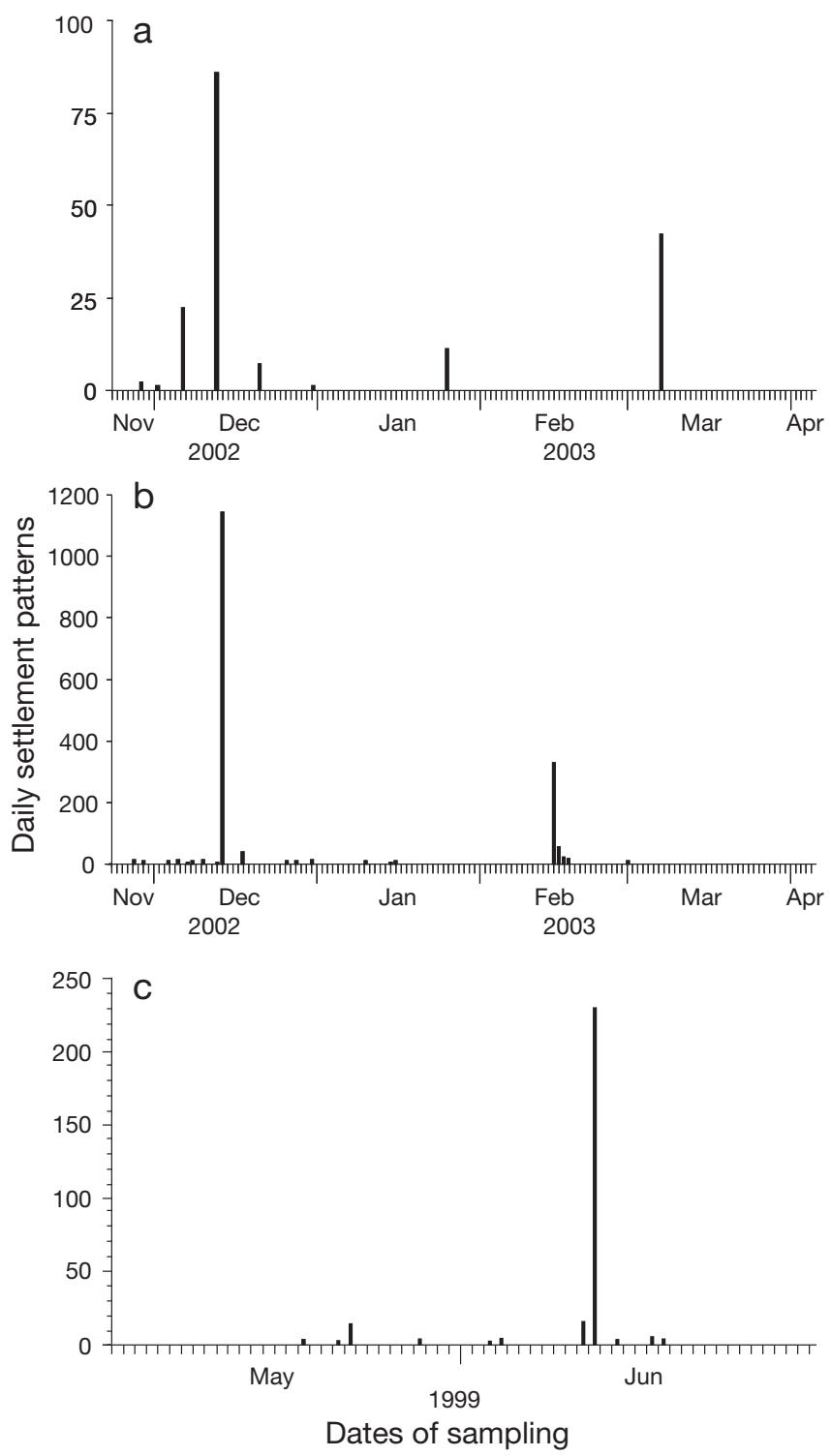

Fig. 1. Diplodus vulgaris and D. sargus. Daily settlement patterns of $D$. vulgaris in the winter season (22 November 2002 to 4 April 2003) at (a) Banyuls and (b) St Marie, and (c) of D. sargus in the summer season (1 May 1999 to 30 June 1999) at St Marie cohort abundance over time followed an exponential model (Abundance $=$ Initial abundance $\times \operatorname{Exp}[-0.019$ $\times$ Days since settlement], $\mathrm{r}^{2}=0.79, \mathrm{n}=120, \mathrm{p}<0.001$ at Banyuls; Abundance $=$ Initial abundance $\times$ $\operatorname{Exp}[-0.017 \times$ Days since settlement $], r^{2}=0.87, \mathrm{n}=$ $120, \mathrm{p}<0.001$ at St Marie). Mortality for the D. sargus cohort was $80.8 \%$ after 4 mo at St Marie (Fig. 2c). The cohort decrease across time followed an exponential model (Abundance $=$ Initial abundance $\times$ $\operatorname{Exp}\left[-0.021 \times\right.$ Days since settlement $, \mathrm{r}^{2}=0.91, \mathrm{n}=$ $120, \mathrm{p}=0.007)$.

\section{Growth}

Diplodus recruits grew on average from 8.8-10.0 mm at settlement to $27.1-29.7 \mathrm{~mm}$ for $D$. vulgaris and to $57.0 \mathrm{~mm}$ for D. sargus after 4 mo (Table 1). Growth showed a significant difference with time and species (2-way ANOVA; time: $F_{4,285}=16889.64, \mathrm{p}<0.001$; species: $\left.F_{2,285}=9042.21, \mathrm{p}<0.001\right)$. The interaction between the 2 factors was also significant (Time $\times$ Species: $F_{8,285}=1492.73, \mathrm{p}<0.001$ ). The growth of $D$. vulgaris cohorts was different between the 2 sites (Student-Newman-Keuls post hoc tests; $\mathrm{p}<0.001$ ), and $D$. sargus showed faster growth than $D$. vulgaris (Student-Newman-Keuls post hoc tests; $\mathrm{p}<0.001$ ). The coefficient of variation (CV) in size of both Diplodus species decreased from settlement over 4 mo (Fig. 3a). This decrease was significantly correlated with time at St Marie for both Diplodus species (Spearman correlation test ${ }_{i} D$. vulgaris: $\mathrm{r}=-0.90, \mathrm{p}=0.03 ; D$. sargus: $\mathrm{r}=$ -0.94, $\mathrm{p}=0.03$ ), but not for $D$. vulgaris at Banyuls ( $\mathrm{r}=$ $-0.78, \mathrm{p}=0.07)$.

\section{Parasitism}

The only parasites that were found in juveniles of both Diplodus vulgaris in the winter and D. sargus in the summer were encysted digeneans in muscle. The cysts were found at the base of the dorsal and caudal fins. Parasite abundance decreased significantly with time $\left(F_{5,342}=2.60, \mathrm{p}=0.03\right)$, and this decrease varied according to species $\left(F_{2,342}=8.58, \mathrm{p}<0.001\right)$. The interaction between the 2 factors was not significant $\left(F_{10,342}=0.84, \mathrm{p}=0.56\right) . D$. vulgaris at both sites was more parasitised than D. sargus (Student-NewmanKeuls post hoc tests; $\mathrm{p}<0.001$; Table 1 ). The prevalence of $D$. vulgaris at both sites decreased from settlement over 4 mo (Fig. 3b), but not significantly (Banyuls: $\mathrm{r}=-0.77, \mathrm{p}=0.10$; St Marie: $\mathrm{r}=-0.82, \mathrm{p}=$ $0.08)$. In contrast, the prevalence of $D$. sargus showed a significant decrease over time $(r=-0.82, p=0.03$; Fig. 3b). 


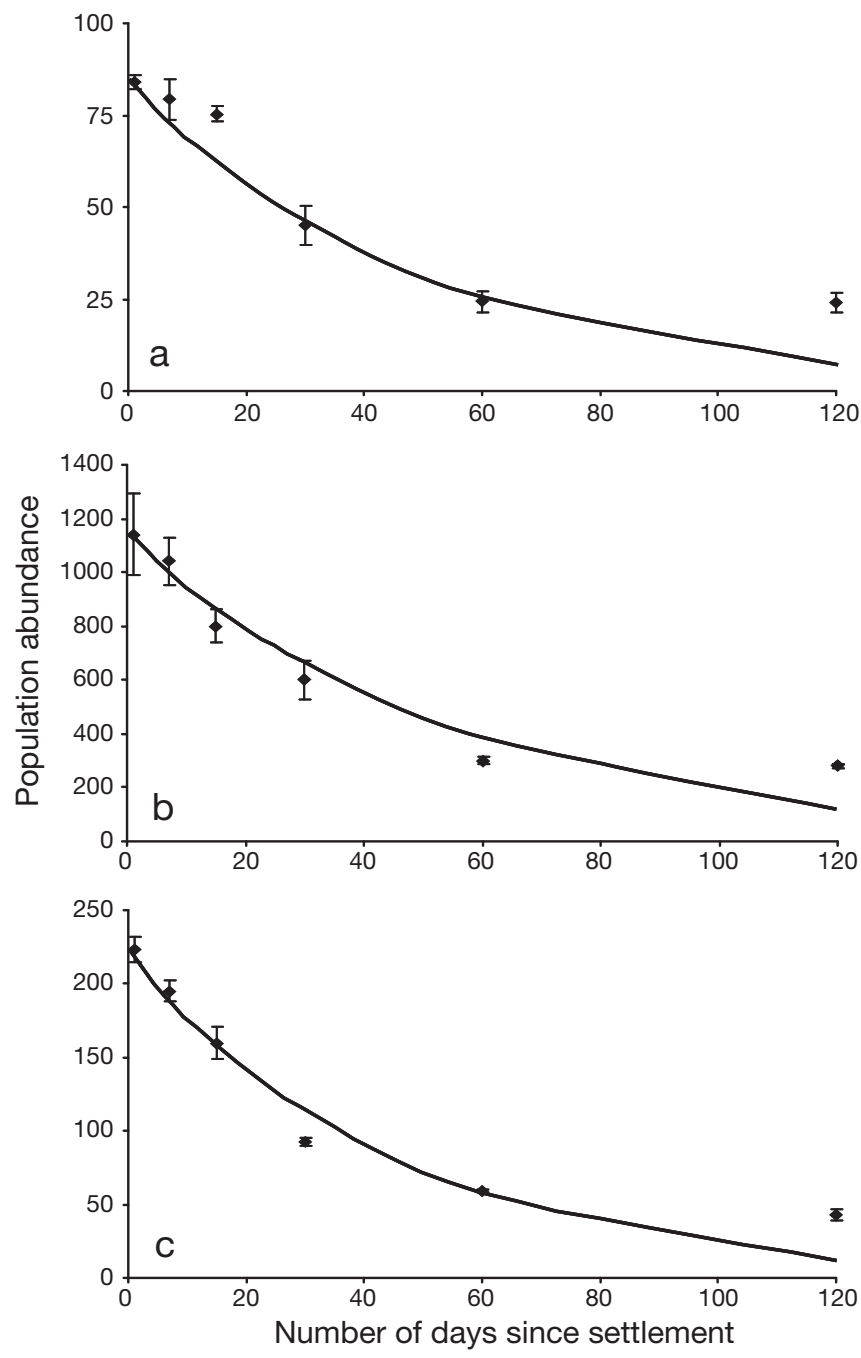

Fig. 2. Diplodus vulgaris and D. sargus. Decrease in population abundance over the first 4 mo post-settlement for (a) a $D$. vulgaris cohort arriving on 10 December 2002 at Banyuls; (b) a D. vulgaris cohort arriving on 13 December 2002 at St Marie; and (c) a D. sargus cohort arriving on 12 June 2003 at St Marie. Population decrease was monitored on the following days post-settlement: Days 0, 7, 15, 30, 60 and 120. Error bars represent the SE of 3 successive underwater visual counts along the jetty or inside the bay

\section{DISCUSSION}

Our study examined patterns of survival and growth, as well as within-cohort variance in length and parasite load over a period of 4 mo post-settlement for 2 closely related reef fishes in the Mediterranean. Mortality of Diplodus juveniles in each cohort was high (between 71 and $81 \%$; Fig. 2), and mortality did not seem to act randomly in $D$. vulgaris and $D$. sargus cohorts.

As the present work is based on surveys of the same cohort through time, before interpreting the results, we must be sure that fish surveyed belong to the same cohort (i.e. no overlap between successive settlement pulses and no emigration of individuals out of the surveyed areas). At settlement, Diplodus larvae are transparent and $\sim 8$ to $10 \mathrm{~mm}$ total length. Planes et al. $(1998,1999)$ showed that from the first post-settlement day, they quickly develop juvenile pigmentation patterns. This allows us to distinguish between Diplodus individuals on the first day of settlement and older conspecifics (i.e. larvae arriving on the second pulse being clearly identifiable from those from the first pulse). Thus, after the $D$. vulgaris cohort on 10 December and the $D$. sargus cohort on 12 June, the next significant settlement pulse did not occur before 1 mo (Fig. 1). This absence of overlap between successive settlement pulses allowed us to identify and easily follow one larval cohort during several months.

The most difficult problem, when following mortality, is to distinguish between mortality and emigration of individuals out of the survey areas. Several studies showed that Diplodus juveniles had a limited migration (about $50 \mathrm{~m}$ around the settlement habitat) and did not cross unsuitable habitats such as sandy areas (Harmelin-Vivien et al. 1995, Planes et al. 1998, 1999). Romans (2003) monitored D. vulgaris and D. sargus daily during the winter and summer seasons, respectively. He showed that no Diplodus juvenile was observed between jetties or bays, and that bays and jetties were the only settlement habitats of Diplodus in

Table 1. Diplodus vulgaris and D. sargus. Mean $( \pm \mathrm{SE})$ of size and digenean parasite abundance examined to determine the causes of mortality of $D$. vulgaris and $D$. sargus at 2 sites in the Mediterranean Sea during the first 4 mo post-settlement. Parameters are given on the first day of settlement (Day 0) and then days after settlement. na: data not available

\begin{tabular}{|c|c|c|c|c|c|c|}
\hline \multirow[t]{3}{*}{ Day } & \multicolumn{3}{|c|}{ Standard length $(\mathrm{mm})(\mathrm{n}=20)$} & \multicolumn{3}{|c|}{ Parasite abundance (ind. fish $\left.{ }^{-1}\right)(\mathrm{n}=20)$} \\
\hline & D. vulgaris & D. vulgaris & D. sargus & D. vulgaris & D. vulgaris & D. sargus \\
\hline & Banyuls & St Marie & St Marie & Banyuls & St Marie & St Marie \\
\hline 0 & $8.96( \pm 0.53)$ & $8.85( \pm 0.53)$ & $10.00( \pm 0.01)$ & 7 & 13 & 4 \\
\hline 7 & $9.43( \pm 0.54)$ & $9.68( \pm 0.52)$ & $11.8( \pm 0.10)$ & 10 & 6 & 4 \\
\hline 15 & $13.13( \pm 0.52)$ & $12.75( \pm 0.54)$ & $15.69( \pm 0.11)$ & 6 & 9 & 1 \\
\hline 30 & $16.18( \pm 0.62)$ & $15.22( \pm 0.76)$ & $25.29( \pm 0.21)$ & 5 & 4 & 0 \\
\hline 60 & $20.13( \pm 0.83)$ & $19.86( \pm 0.60)$ & $35.87( \pm 0.30)$ & 4 & 4 & 0 \\
\hline 120 & $29.72( \pm 0.92)$ & $27.06( \pm 0.82)$ & $57.02( \pm 0.23)$ & na & na & 0 \\
\hline
\end{tabular}



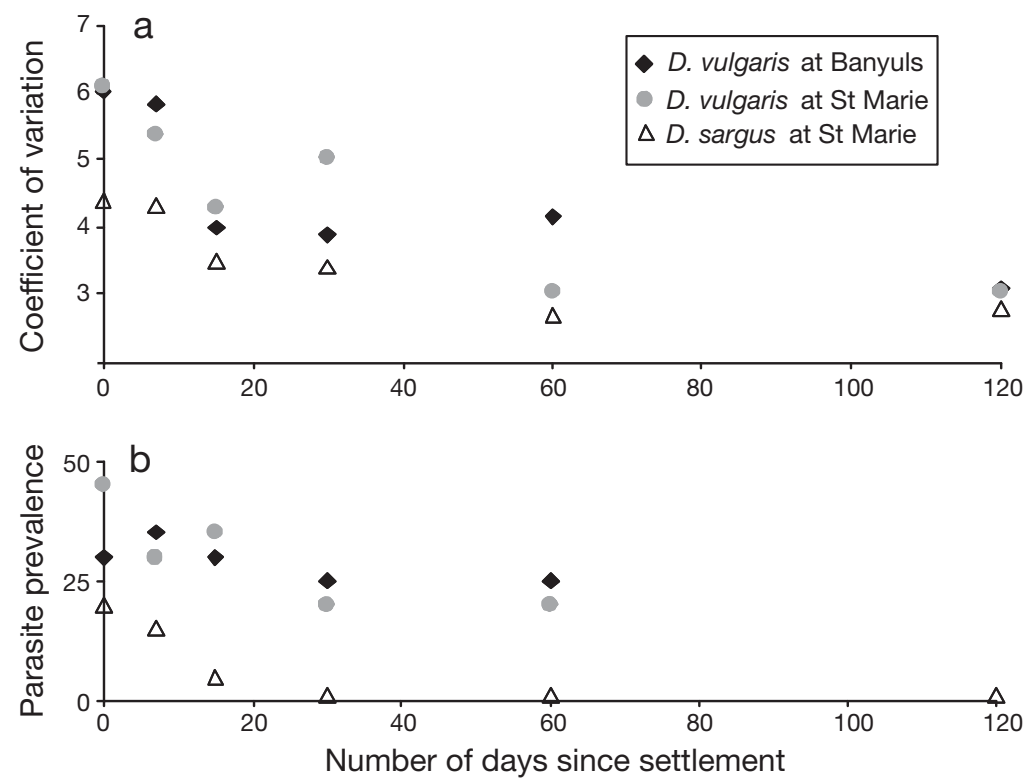

Fig. 3. Diplodus vulgaris and D. sargus. Evolution in (a) the coefficient of variation of size and (b) parasite prevalence (\% of parasitised fish) of both Diplodus species at both sampling sites over the first 4 mo post-settlement

the sampling areas (Banyuls and St Marie). This habitat restriction during the first post-settlement months made the fish easy to count in settlement habitats, and we assumed that fish did not move between bays or jetties.

Mortality was influenced by size (Fig. 3a). Indeed, the complete spectrum of variability in size of recently settled juveniles at settlement was not transferred through to the Diplodus cohorts 4 mo later, suggesting that, contrary to expectations of random fish mortality, surviving fish show less variation in size (e.g. Vigliola \& Meekan 2002, Hoey \& McCormick 2004, Gagliano et al. 2007). Mortality processes can thus operate in a size-selective manner, with viability selection acting either on larger or smaller fish sizes in Diplodus cohorts. Meekan et al. (2006) showed that selective mortality acted to preferentially remove fish that were slow-growing in Spratelloides gracilis cohorts ('bigger is better' template, reviewed by Sogard 1997). Examples of viability selection acting on smaller fish sizes have also been reported, typically in response to selective predation on larger fish by non-gape-limited predators, such as birds or humans (Fenberg \& Roy 2008). Our sampling protocol was not able to determine if viability selection acted either on larger or smaller fish sizes; only the back calculation of size from otoliths allows the direction of size-selective mortality to be identified (e.g. Vigliola \& Meekan 2002, Vigliola et al. 2007). Nevertheless, our sampling protocol highlighted that the timing and strength of size selection varied according to location and Diplodus species
(Fig. 3a), with the strongest size selection present in the cohort with the highest initial density (D. vulgaris at St Marie). The non-significant decrease in the coefficient of variation in length for D. vulgaris at Banyuls could thus be explained by a low initial density (172 D. vulgaris larvae at Banyuls compared to 1741 D. vulgaris larvae at St Marie). These results may therefore be consistent with density-dependent mortality selecting against individual variation (Vigliola et al. 2007). However, processes other than selective mortality could also result in a decrease in the coefficient of variation in length of fish over time (e.g. compensatory growth, size-dependent emigration; Arendt 1997, Carlson et al. 2004, Gagliano \& McCormick 2007).

The most significant result, in terms of processdriven analysis, is certainly that parasite abundance of both Diplodus species at both sites decreased significantly with time (Table 1), and prevalence decreased significantly with time for D. sargus at St Marie (Fig. 3b). Many parasites adversely affect their hosts or modify host behaviour to increase the host's vulnerability to predation in order to enhance the parasite's transmission to the definitive hosts (e.g. Combes 1995, Sasal et al. 2000, Bourque et al. 2006). In the case of the digenean metacercarian cyst found in $D$. vulgaris and $D$. sargus, the only transmission pathway after Diplodus is via their predation (Combes 1995). These digenean cysts were located at the basal section of dorsal and caudal fins, the most important fins for swimming performance in fish. Therefore, digeneans may have evolved to reduce the swimming capability of their intermediate host in order to increase predation by the final host. Alternatively, reduced swimming capacity of fish would diminish their foraging ability and reduce their condition. Regardless of the mechanism, selective mortality appears to be acting on parasite load. However, the influence of parasitism on mortality must be treated with caution, as less than $50 \%$ of Diplodus juveniles were infected with parasites at settlement and the abundance of parasites on infected individuals was low (1 to 13 fish $^{-1}$; Table 1).

\section{CONCLUSIONS}

Selective mortality appears to be acting on both fish size and parasite infection. If mortality of recently settled juveniles was random with respect to fish size and parasite load, the complete spectrum of variability of these phenotypes would be transferred through to the adult population of Diplodus species, which is contrary to our findings. The conclusions of this study should 
nevertheless be treated with caution, as selection pressures are often context-dependent and are likely to fluctuate both in time and space due to variation in biotic and abiotic factors (Carlson \& Quinn 2007). For example, the coefficient of variation in size significantly decreased with time for $D$. vulgaris at St Marie, but not at Banyuls. Holmes \& McCormick (2006) showed that the extent to which mortality was size selective immediately after settlement can differ among locations separated only by hundreds of metres. The conflicting results in our study suggest that mortality at settlement is not always acting on fish with a small body size and/or high parasite load, and that mortality depends on conditions into which individuals settle (Gagliano \& McCormick 2007). Therefore, future studies on other species exploring the spatio-temporal variability of these processes should test the hypotheses outlined here in terms of size- and parasitism-selective mortality of marine species.

\section{LITERATURE CITED}

Allen JD (2008) Size-specific predation on marine invertebrate larvae. Biol Bull (Woods Hole) 214:42-49

> Almany GR, Webster MS (2006) The predation gauntlet: early post-settlement mortality in reef fishes. Coral Reefs 25: $19-22$

Arendt JD (1997) Adaptive intrinsic growth rates: integration across taxa. Biol Bull (Woods Hole) 72:149-177

Arnold SJ, Wassersug RJ (1978) Differential predation on metamorphic anurans by garter snakes: social behaviour as a possible defence. Ecology 59:1014-1022

Bourque JF, Dodson JJ, Ryan DAJ, Marcogliese DJ (2006) Cestode parasitism as a regulator of early life-history survival in an estuarine population of rainbow smelt Osmerus mordax. Mar Ecol Prog Ser 314:295-307

Carlson SM, Quinn TP (2007) Ten years of varying lake level and selection on size-at-maturity in sockeye salmon. Ecology 88:2620-2629

Carlson SM, Hendry AP, Letcher BH (2004) Natural selection acting on body size, growth rate and compensatory growth: an empirical test in a wild trout population. Evol Ecol Res 6:955-973

Combes C (1995) Interactions durables: écologie et évolution du parasitisme. Masson edition, Paris (in French)

Doherty PJ (2002) Variable replenishment and the dynamics of reef fish populations. In: Sale PF (ed) Coral reef fishes: dynamics and diversity in a complex ecosystem. Academic Press, San Diego, CA, p 327-358

Doherty PJ, Dufour V, Galzin R, Hixon MA, Planes S (2004) High mortality at settlement is a population bottleneck for a tropical surgeonfish. Ecology 85:2422-2428

Fenberg PB, Roy K (2008) Ecological and evolutionary consequences of size-selective harvesting: How much do we know? Mol Ecol 17:209-220

Editorial responsibility: Thomas Turner,

Albuquerque, New Mexico, USA
Gagliano M, McCormick MI (2007) Compensating in the wild: Is flexible growth the key to early juvenile survival? Oikos 116:111-120

Gagliano M, McCormick MI, Meekan MG (2007) Survival against the odds: ontogenetic changes in selective pressure mediate growth-mortality trade-offs in a marine fish. Proc R Soc Lond 274:1575-1582

Harmelin-Vivien ML, Harmelin JG, Chauvet C, Duval C and others (1985) Evaluation visuelle des peuplements et populations de poissons: méthodes et problèmes. Rev Ecol (Terre Vie) 40:467-539 (in French)

- Harmelin-Vivien ML, Harmelin J, Leboulleux V (1995) Microhabitat requirements for settlement of juvenile sparid fish on Mediterranean rocky shores. Hydrobiologia 300-301: 309-320

$>$ Hoey AS, McCormick MI (2004) Selective predation for low body condition at the larval-juvenile transition of a coral reef fish. Oecologia 139:23-29

Holmes TH, McCormick MI (2006) Location influences sizeselective predation on newly settled reef fish. Mar Ecol Prog Ser 317:203-209

Kingsolver JG, Hoekstra HE, Hoekstra JM, Berrigan D and others (2001) The strength of phenotypic selection in natural populations. Am Nat 157:245-261

> Lecchini D, Planes S, Galzin R (2007) The influence of habitat characteristics and conspecifics on attraction and survival of coral reef fish juveniles. J Exp Mar Biol Ecol 341:85-90

- Meekan MG, Vigliola L, Hansen A, Doherty PJ, Halford A, Carleton JH (2006) Bigger is better: size-selective mortality throughout the life history of a fast-growing clupeid, Spratelloides gracilis. Mar Ecol Prog Ser 317:237-244

> Planes S, Jouvenel JY, Lenfant P (1998) Density dependent in post-recruitment processes of juvenile sparids in the littoral of the Mediterranean Sea. Oikos 83:293-300

Planes S, Macpherson E, Biagi F, Garcia-Rubies A and others (1999) Ecological and biological implications of spatiotemporal variability in growth of juvenile sparid fishes from the Mediterranean littoral. J Mar Biol Assoc UK 79: $137-143$

Romans P (2003) Facteurs intrinsèques et extrinsèques de variabilité du recrutement chez les poissons marins. PhD thesis, University of Perpignan (in French)

Sasal P, Durand P, Faliex E, Morand S (2000) Experimental approach to the importance of parasitism in biological conservation. Mar Ecol Prog Ser 198:293-302

Sogard SM (1997) Size-selective mortality in the juvenile stage of teleost fishes: a review. Bull Mar Sci 60: 1129-1157

Stearns SC (1992) The evolution of life histories. Oxford University Press, Oxford

Vigliola L, Meekan MG (2002) Size at hatching and planktonic growth determines post-settlement survivorship of a coral reef fish. Oecologia 131:89-93

> Vigliola L, Doherty PJ, Meekan MG, Drown DM, Jones ME, Barber PH (2007) Genetic identity determines risk of post-settlement mortality of a marine fish. Ecology 88: 1263-1277

Werner EE (1988) Size, scaling and the evolution of complex life cycles. In: Ebenman B, Perssons L (eds) Sizestructured populations. Springer-Verlag, Berlin, p 61-71

Submitted: December 23, 2008; Accepted: June 29, 2009

Proofs received from author(s): August 4, 2009 